\title{
On the role of cost-effectiveness thresholds in healthcare priority setting
}

Jonathan Siverskog and Martin Henriksson

The self-archived postprint version of this journal article is available at Linköping University Institutional Repository (DiVA):

http://urn.kb.se/resolve?urn=urn:nbn:se:liu:diva-175299

N.B.: When citing this work, cite the original publication.

Siverskog, J., Henriksson, M., (2021), On the role of cost-effectiveness thresholds in healthcare priority setting, International Journal of Technology Assessment in Health Care, 37(1), e23. https://doi.org/10.1017/So266462321000015

Original publication available at:

https://doi.org/10.1017/So266462321000015

Copyright: Cambridge University Press

http://www.cambridge.org/uk/ 


\title{
ON THE ROLE OF COST-EFFECTIVENESS THRESHOLDS IN HEALTH CARE PRIORITY SETTING*广
}

\author{
Jonathan Siverskog ${ }^{1}$ \\ Martin Henriksson ${ }^{1}$ \\ ${ }^{1}$ Centre for Medical Technology Assessment, Linköping University
}

\begin{abstract}
In the past few years, empirical estimates of the marginal cost at which health care produces a quality-adjusted life year $(\mathrm{k})$ have begun to emerge. In theory, these estimates could be used as cost-effectiveness thresholds by health-maximizing decision makers but prioritization decisions in practice often include other considerations than just efficiency. Pharmaceutical reimbursement in Sweden is one such example, where the reimbursement authority (TLV) uses a threshold range to give priority to disease severity and rarity. In this paper, we argue that estimates of $\mathrm{k}$ should not be used to inform threshold ranges. Instead, they are better used directly in health technology assessment (HTA) to quantify how much health is forgone when a new technology is funded in place of other health care services. Using a recent decision made by TLV as a case, we show that an estimate of $\mathrm{k}$ for Sweden implies that reimbursement meant forgoing 8.6 quality-adjusted life years (QALYs) for every QALY that was gained. Reporting cost-effectiveness evidence as QALYs forgone per QALY gained has several advantages: i) it frames the decision as assigning an equity weight to QALYs gained, which is more transparent about the trade-off between equity and efficiency than determining a monetary cost per QALY threshold, ii) it makes it less likely that decision makers neglect taking the opportunity cost of reimbursement into account by making it explicit, and iii) it helps communicate the reason for sometimes denying reimbursement in a way that might be less objectionable to the public than current practice.
\end{abstract}

\footnotetext{
${ }^{*}$ Acknowledgements: We are grateful for the comments of David Tamblyn and two anonymous reviewers as well as the advice of an anonymous legal professional on our account of legislation on health care priority setting. Funding statement: This project was funded in part by Region Östergötland. Conflicts of interest: Martin Henriksson is a member of the Pharmaceutical Benefits Board at The Dental and Pharmaceutical Benefits Agency and voted to not reimburse Orkambi. The authors declare that they have no further conflicts of interest.

${ }^{\dagger}$ This is a postprint. Published version: Siverskog, J., \& Henriksson, M. (2021). On the role of costeffectiveness thresholds in healthcare priority setting. International Journal of Technology Assessment in Health Care, 37(1), E23. https://doi.org/10.1017/S0266462321000015
} 


\section{Introduction}

In the past few years, several studies have reported empirical estimates of the marginal cost at which health systems produce a quality-adjusted life year (QALY) (e.g., 1-4). These estimates reflect an expectation on how much health (as measured by QALYs) would be gained or lost from small changes in the health care budget and can be used to determine whether new health technologies are expected to produce more health than is forgone by funding them. Rather than to identify a specific alternative which is forgone when a new technology is funded, this assumes that we can expect the alternative use of the funds to be as productive as additional funding has been on average in the past. Thus, estimates of the marginal cost at which health systems produce a QALY (which we shall henceforth refer to as $k$ ) could provide a long-sought empirical basis for costeffectiveness thresholds.

However, the role that cost-effectiveness thresholds could or should play in health care decision making is somewhat unclear since priority setting in health care may have other objectives than efficiency (5). Most notable among these is equity, which has been shown to be a more frequent criterion in health care decision making than cost effectiveness (6). For this reason, it is important not to conflate $k$ with the threshold used either explicitly or implicitly by decision makers to determine if the cost per QALY gained with a new technology is acceptable $(7,8)$. Such a threshold would only equal $k$ if efficiency (i.e., maximizing the number of QALYs produced by the health system) were the sole objective of the decision maker.

An example of a decision maker with other objectives than efficiency is The Dental and Pharmaceutical Benefits Agency (TLV), which is responsible for pharmaceutical reimbursement decisions in Sweden. TLV does not have an official cost-effectiveness threshold but has made a few statements about established practices that define a threshold range. It will generally reimburse drugs with an incremental cost-effectiveness ratio (ICER) below SEK 1 million ( EUR 100,000) per QALY for treatment of conditions it assesses to be very severe (9) and may accept an ICER of up to SEK 2 million $(\sim$ EUR 200,000) per QALY if the condition is also rare $(10)$. These practices are intended to reflect its remit to strike a balance between needs, non-discrimination, and cost effectiveness when making decisions about reimbursement.

In this paper, we characterize TLV's remit as making trade-offs between equity and efficiency and use a recent reimbursement decision made by TLV as a case to propose a role for empirical estimates of $k$ in health care priority setting with equity concerns. We argue that estimates of $k$ should not be used by decision makers to somehow inform a monetary cost per QALY threshold (or threshold range) that takes both efficiency and equity criteria into account. Instead, estimates of $k$ are better used directly in health technology assessment (HTA) and cost-effectiveness analysis (CEA) to quantify the health that is forgone by funding new technologies instead of other health care services. Thus, funding decisions would no longer be based on a monetary cost per QALY but on the number of QALYs forgone per QALY gained, with the implication that a decision can be understood as a ruling on the relative importance of QALYs gained and QALYs forgone. This is more transparent about the trade-off between equity and efficiency than determining a monetary cost per QALY threshold that is supposed to reflect both criteria. More importantly, expressing costs in terms of health forgone makes the opportunity cost of funding more salient to decision makers and the reason for negative decisions easier to communicate to the public.

The quantification of health forgone and the concept of net health benefit (NHB) is already well established in the health economics literature $(7,11)$. The main contribution 
of this paper is to show how cost-effectiveness evidence can be made more relevant to decision making concerned with other objectives than efficiency. Given the important role of equity criteria in health care priority setting, HTA's and in particular CEA's preoccupation with efficiency has been identified as a potential limitation to its usefulness $(12,13)$ and there are methods that seek to integrate equity concerns in CEA (14). However, such methods may run the risk of making assumptions about the priority of different equity-related attributes that do not align with those of the decision maker. A key message of this paper is that estimates of $k$ offer a way for HTA to report costeffectiveness evidence so that it is more relevant to an equity-efficiency trade-off, while remaining neutral with respect to how that trade-off is eventually made.

In what follows, we begin with a brief account of health care priority setting and pharmaceutical reimbursement in Sweden before illustrating our arguments using a recent reimbursement decision as a case.

\section{Health care priority setting and pharmaceutical reim- bursement in Sweden}

In Sweden, patients' prescription pharmaceutical purchases are subsidised via The Pharmaceutical Benefit. In the Pharmaceutical Benefits Act (15), TLV is tasked with deciding which pharmaceuticals are included in The Benefit (i.e., reimbursed). This legislation states that a pharmaceutical is to be reimbursed if its costs appear reasonable from medical, humanitarian, and economic perspectives. What TLV should consider in their decision making is further dictated by The Health and Medical Services Act (16) and The Ethical Platform, described in the government bill on priority setting in health care (17), which amends The Act. The Ethical Platform enumerates three guiding principles for all health care prioritizations in Sweden:

1. the human-dignity principle: all human beings are equal and have the same rights, regardless of their personal characteristics and functions in society;

2. the needs-solidarity principle: resources should be allocated based on needs;

3. the cost-effectiveness principle: in a choice between different services or interventions, health care should strive for a reasonable relation between costs and effects, measured in terms of improved health and quality of life.

The Bill states that the cost-effectiveness principle is subordinated to the two former principles but also that this hierarchy primarily relates to prioritization decisions at the individual level. While The Bill acknowledges, in passing, that budget restrictions may imply that all needs cannot be met and that it is important for health care at large to strive for cost effectiveness, it does not address prioritization with respect to such trade-offs. Thus, legislators have provided some intentions but it has de facto been left to decision makers to judge how the cost-effectiveness principle is appropriately operationalized in relation to the other principles, which if read by the letter, may seem to give absolute priority to needs and non-discrimination.

TLV's practice has been to base reimbursement decisions primarily on cost per QALY gained and an informal, case-by-case assessment of disease severity. Accepting a higher cost per QALY for treatment of severe disease has been a way to operationalize the needssolidarity principle (9). The human-dignity principle has motivated TLV's premium on rarity (9) and influences its views on the inclusion of indirect costs (18). Although TLV officially recommends a societal perspective in its guidelines for economic evaluation 
(19), it has been moving towards the use of a health care sector perspective as its base case and has made a statement that it will no longer consider production gains from added life years since it discriminates against patients who are not part of the labor force (18).

Cost-effectiveness evidence has, in practice, taken on a central role in the reimbursement process but it is clear that efficiency cannot be interpreted as TLV's sole objective and that equity is more than just a minor added concern.

\section{The equity-efficiency trade-off}

In 2018, TLV reimbursed Orkambi, accepting an ICER of SEK 1.54 million ( EUR $150,000)$ per QALY compared to standard of care due to the severity and rarity of cystic fibrosis for which the drug is indicated (20). A recent study (4) (by the authors) estimates $k$ in Sweden at SEK 180,000 ( EUR 18,000) per QALY, which implies that Orkambi was cost ineffective (i.e., implied a net health loss to the Swedish health system), but that information alone would have done little to inform TLV's decision. Instead of thinking of $k$ as a threshold against which to judge the ICER, it should be seen as an input in CEA which allows the health opportunity cost (7) of reimbursement to be quantified. If Orkambi had not been reimbursed, then other health care services would (or at least could) have been funded in its place. Granting reimbursement meant forgoing the health that those services would have generated.

Orkambi was expected to affect 245 patients with an incremental gain of 1.65 QALYs per patient. The expected incremental cost per patient was SEK 2.54 million, including pharmaceutical and other health care costs (21). All patients treated with Orkambi would then be expected to gain

$$
\Delta Q=1.65 \text { QALYs } \times 245=404 \text { QALYs }
$$

but other patients (which could potentially include patients treated with Orkambi) would have to forgo

$$
\frac{\Delta C}{k}=\frac{\text { SEK } 2,540,000 \times 245}{\text { SEK } 180,000 / \text { QALY }}=3457 \text { QALYs } .
$$

The NHB of Orkambi would be

$$
\mathrm{NHB}=404 \text { QALYs }-3457 \text { QALYs }=-3053 \text { QALYs. }
$$

The NHB is more explicit about the degree of cost ineffectiveness and the population health price of prioritizing equity than the ICER, but we believe that decision makers may find it hard to make sense of its magnitude (at least we do). Another way to express the same information, which emphasizes the relative priority given to patients, is the number of QALYs forgone per QALY gained

$$
\frac{\Delta C / k}{\Delta Q}=\frac{3457 \text { QALYs forgone }}{404 \text { QALYs gained }}=8.6 \text { QALYs forgone per QALY gained }
$$

Presented with this information, TLV's decision would have boiled down to a judgement on whether the health of patients set to receive Orkambi were at least 8.6 times as important as that of unidentified patients. This is, we believe, the most relevant way to express cost-effectiveness evidence if it is intended to inform decision making that is concerned with a trade-off between efficiency and equity. 


\section{Equity weighting?}

Using QALYs forgone per QALY gained to inform decision making is closely related to the notion of equity weighting $(22,23)$, but does not assign different equity weights to different attributes. Instead, it frames a decision in terms of a judgement on whether the equity-bearing characteristics of those that gain are important enough to justify an overall health loss. If we let $w$ denote the relative equity weight of QALYs gained over QALYs forgone, decision makers would decide to fund a new technology if

QALYs forgone $<w \times$ QALYs gained.

Since this can also be stated as

$$
\frac{\text { QALYs forgone }}{\text { QALYs gained }}<w,
$$

QALYs forgone per QALY gained is the minimum equity weight required to justify a positive decision. However, it can also be equivalently stated that decision makers would decide to fund a new technology if

$$
\frac{\Delta C}{\Delta Q}<k w .
$$

That is, if the monetary cost per QALY is below a threshold that reflects both $k$ and $w$. Thus, there is nothing inherently incorrect in decision makers using a threshold range and accepting a higher cost per QALY for, e.g., technologies targeting more severe diseases. The advantage of basing a decision on QALYs forgone per QALY gained is that it separates the efficiency criterion from the equity criteria, which may help decision makers be more explicit about and more consistent in their prioritizations. It is not impossible for TLV to use its current threshold range consistently, but being consistent is bound to be more difficult when the judgement on the equity weight of health gained is mixed up with an implicit estimate of how much health is forgone.

It may appear as if a logical next step in aiding decision making could be to incorporate empirical estimates of equity weights in CEA, but this would not necessarily be helpful. If weights are elicited from the general public they may reflect preferences for, e.g., prioritising the young over the old or deprioritising self-induced illness (24). At least in Sweden's case, such weights could conflict with the human-dignity principle on non-discrimination set out in The Ethical Platform, which TLV is tasked to consider.

From another perspective, we can regard it as a question of within what parameters decision makers' deliberation should take place (12). Judgements on both $k$ and $w$ are currently implicit and left up to the decisions makers' discretion, but with the emergence of empirical estimates of $k$ we are at least approaching a stage at which $k$ should no longer be a parameter that is implicitly defined through deliberation. $w$ is, arguably, more of a value judgement but if decisions were based on QALYs forgone per QALY gained, we could expect equity weights to be established through precedent from previous decisions. The deliberative process may be informed by public opinion, but decision makers' deliberation about equity weights appears necessary to take ethical principles in health care priority setting into account.

It is, of course, such a process that has led to TLV's current threshold range. However, there is good reason to believe that decisions based on a monetary cost per QALY may fail to take the opportunity cost of a decision into account, and therefore set precedents that do likewise. One is given to wonder whether TLV's practice to accept SEK 2 million per QALY for treatments targeting very severe and rare diseases would have 
evolved similarly if the information had been framed as 11 QALYs forgone per QALY gained?

\section{Health versus health versus money versus health}

Another advantage of QALYs forgone per QALY gained is that it is explicit about the opportunity cost of funding a new technology. This advantage is intimately linked to an asymmetry between positive and negative reimbursement decisions. Positive decisions are never going to be faced with much protest, but negative decisions can be very uncomfortable to make. This is because the patients affected by a negative decision are identifiable and may be represented by vocal interest organizations. The patients who bear the opportunity cost of a positive reimbursement decision (whose health is forgone), on the other hand, are unidentified and in general lack strong advocacy. It may therefore be very tempting to ignore the opportunity cost and/or very easy to forget it (25).

The tendency to not consider opportunity cost unless reminded of it has been referred to as opportunity cost neglect (26) and it has recently been suggested that this may pose a problem in health care priority setting (27). We submit that presenting decision makers with ICERs is a recipe for such neglect, since the binary decision rule of ICER above or below threshold does not properly communicate what benefit is forgone. Framing the information as a monetary cost per QALY makes the alternative use of funds implicit and therefore very easy to ignore or forget. If the relevant trade-off is in fact between the health of one patient group and that of another, then health versus health is, inarguably, a more appropriate way of expressing the consequences predicted by CEA than money versus health.

In the case of Orkambi, the straightforward representation of the trade-off was 8.6 QALYs forgone per QALY gained. This would have allowed TLV to be more explicit about its concern for equity and the relative priority given to different patient groups, as well as helped TLV avoid neglecting the opportunity cost of reimbursement. It would probably also have proved a better support for making (and communicating the reasons for) a negative decision (28), had TLV found that this was an appropriate call to make. Stating that the monetary cost per QALY is too high is easily perceived as saying that people's lives are not valuable enough to save. This is a tough sell, even when it is viewed as a relevant trade-off. Again, if it is a health versus health trade-off, there is no good reason to frame it as money versus health.

Finally, when decision makers are tasked to consider both equity and efficiency, an ICER below $k$ should not always lead to a positive reimbursement decision, since QALYs forgone could have higher priority than QALYs gained $(25,28)$. We predict that expressing consequences as QALYs forgone per QALY gained would also aid decision making in this respect

\section{$6 \quad$ Further considerations}

It should be emphasized that applied equity weighting would not be as simple as to determine a single equity weight and to provide a fully consistent framework for making trade-offs between efficiency and equity, it is clear that information on the equity-bearing characteristics of those that forgo health is necessary $(7,23)$. In lack of such information, it would still be a step towards greater clarity if decision makers were to explicitly consider the QALYs forgone by unidentified patients when making resource allocation decisions. 
Further, it should be noted that we have assumed that funding a new technology means forgoing other health care services. It is sometimes argued that decisions should be informed by the willingness to pay for a QALY under the assumption that the health care budget expands to make room for additional spending (28). It is only under the assumption of a fixed budget that other health care services would be forgone, but it remains a fact that spending could be used within health care regardless of actual budget restrictions. The estimates of $k$ that we have referred to can be said to reflect (or at least attempt to reflect) expected alternative use of funds in health care, but QALYs forgone per QALY gained had funds been used to, e.g., reduce waiting lists (29), or increase spending on cardiovascular care (30) may also be found relevant from a "could perspective". Such a perspective introduces some confusion about which $k$ to use, but it could also make it easier to reflect QALYs forgone for which severity or other equity criteria are known.

It should also be noted that the advantages of avoiding monetary costs also apply to NHB. In addition, there are several technical advantages of using net benefit instead of ratio metrics in decision making, particularly in the context of sensitivity analysis (11) or when choosing between different versions of the same technology (31). A subtle advantage of QALYs forgone per QALY gained over NHB is that it is not intended to inform health maximization and therefore gives cost-effectiveness evidence a more clear role in a decision-making context where efficiency is just one of many concerns. For TLV, which is bound by legislation to give great weight to needs and non-discrimination, it may therefore prove to be a helpful metric which, together with NHB, should at the very least accompany the ICER when cost-effectiveness evidence is reported.

Finally, although it is hard to give meaningful interpretation to an ICER without at least an implicit value of $k(31)$, it goes without saying that confidence in this value may be crucial for decision makers to be explicit about it. Thus, for their legitimacy in decision making, the credibility of empirical $k$ estimates is an issue that still demands attention.

\section{Conclusion}

When decision makers are concerned with equity and efficiency, it is not meaningful to think of $k$ as a threshold. We have argued that it is better to include $k$ at the stage of evaluation, which means reporting the number of QALYs forgone per QALY gained (or the NHB). This does not eliminate the importance of decision deliberation since decision makers still have to judge if the equity weight for QALYs gained is greater than the number of QALYs forgone per QALY gained. However, it makes the deliberation less muddled by separating the issue of equity from that of efficiency. This will make trade-offs more transparent and may help decision makers be more consistent in their prioritizations. The main advantage of the suggested approach is that it avoids framing trade-offs as money versus health. This is preferable since money versus health appears more likely to lead to opportunity cost neglect on part of decision makers and difficulties in communicating the reasons for denying reimbursement when such a decision is warranted. Presenting decision makers with 8.6 QALYs forgone for every QALY gained may not lead to the same decision as presenting them with an ICER of SEK 1.54 million per QALY and a reference to an "empirical threshold" of SEK 180,000 per QALY, even though the statements reflect the same information. 


\section{References}

1. Claxton K, Martin S, Soares M, Rice N, Spackman E, Hinde S, et al. Methods for the estimation of the National Institute for Health and Care Excellence cost-effectiveness threshold. Health Technol Assess. 2015;19:1-503.

2. Edney LC, Afzali HHA, Cheng TC, Karnon J. Estimating the reference incremental cost-effectiveness ratio for the Australian health system. Pharmacoeconomics. 2018;36:239-52.

3. Vallejo-Torres L, Garcia-Lorenzo B, Serrano-Aguilar P. Estimating a costeffectiveness threshold for the Spanish NHS. Health Econ. 2018;27:746-61.

4. Siverskog J, Henriksson M. Estimating the marginal cost of a life year in Sweden's public healthcare sector. Eur J Health Econ. 2019;20:751-62.

5. Cleemput I, Neyt M, Thiry N, De Laet C, Leys M. Using threshold values for cost per quality-adjusted life-year gained in healthcare decisions. Int J Technol Assess Health Care. 2011;27:71-6.

6. Guindo LA, Wagner M, Baltussen R, Rindress D, van Til J, Kind P, et al. From efficacy to equity: Literature review of decision criteria for resource allocation and healthcare decisionmaking. Cost Eff Resour Alloc. 2012;10:9.

7. Sculpher M, Claxton K, Pearson SD. Developing a Value Framework: The Need to Reflect the Opportunity Costs of Funding Decisions. Value Health. 2017;20:2349 .

8. Woods B, Revill P, Sculpher M, Claxton K. Country-Level Cost-Effectiveness Thresholds: Initial Estimates and the Need for Further Research. Value Health. 2016;19:929-35.

9. TLV [Government Document/Internet] Underlag för beslut om subvention - omprövning: Cerezyme (imiglukeras) och Vpriv (velaglukeras alfa) [cited 2020 Apr 8]. Available from: https://www.tlv.se/download/18. 467926b615d084471ac33d95/1510316366212/Bes161219_underlag_for_ beslut_cerezyme_vpriv.pdf.

10. TLV [Internet] TLV accepterar högre kostnad för läkemedel mot sällsynt sjukdom. [cited 2020 Mar 23]. Available from: https://www.tlv.se/omoss/press/nyheter/arkiv/2016-12-20-tlv-accepterar-hogre-kostnadfor-lakemedel-mot-sallsynt-sjukdom.html.

11. Stinnett AA, Mullahy J. Net health benefits: a new framework for the analysis of uncertainty in cost-effectiveness analysis. Med Decis Making. 1998;18:S68-80.

12. Williams AH, Cookson RA. Equity-efficiency trade-offs in health technology assessment. Int $J$ Technol Assess Health Care. 2006;22:1-9.

13. Panteli D, Kreis J, Busse R. Considering Equity in Health Technology Assessment: An Exploratory Analysis of Agency Practices. Int $J$ Technol Assess Health Care. 2015;31:314-23.

14. Johri M, Norheim OF. Can cost-effectiveness analysis integrate concerns for equity? Systematic review. Int J Technol Assess Health Care. 2012;28:125-32. 
15. SFS 2002:160 [Legislation]. Lag om läkemedelsförmåner m.m.

16. SFS 2017:30 [Legislation]. Hälso- och sjukvårdslag.

17. Proposition 1996/97:60 [Legislation]. Prioriteringar inom hälso- och sjukvården.

18. TLV [Internet] Ny tillämpning av etiska plattformen [cited 2020 Mar 6]. Available from: https://www.tlv.se/lakemedel/halsoekonomi/ny-tillampningav-etiska-plattformen.html.

19. TLV [Government Document/Internet] Ändring i Tandvårds- och läkemedelsförmånsverkets allmänna råd (TLVAR 2003:2) om ekonomiska utvärderingar TLVAR 2017:1 [cited 2019 Oct 9]. Available from: https: //www.tlv.se/download/18.467926b615d084471ac3230c/1510316374332/ TLVAR_2017_1.pdf.

20. TLV [Government Document/Internet] Beslut 45/2018 (Orkambi) [cited 2020 Mar 5]. Available from: https://www.tlv.se/download/18. 500ea4181641067957a31b99/1529412747506/bes180614_orkambi.pdf.

21. TLV [Government Document/Internet] Underlag för beslut om subvention Nyansökan: Orkambi (lumakaftor + ivakaftor) [cited 2020 Apr 8]. Available from: https://www.tlv.se/download/18.500ea4181641067957a31c3f/ 1529587605088/bes180614_orkambi_underlag.pdf.

22. Cookson R, Mirelman AJ, Griffin S, Asaria M, Dawkins B, Norheim OF, et al. Using Cost-Effectiveness Analysis to Address Health Equity Concerns. Value Health. 2017;20:206-12.

23. Round J, Paulden M. Incorporating equity in economic evaluations: a multiattribute equity state approach. Eur J Health Econ. 2018;19:489-98.

24. Williams A. Cost-effectiveness analysis: is it ethical? J Med Ethics. 1992;18:711.

25. Claxton K, Sculpher M, Palmer S, Culyer AJ. Causes for concern: is NICE failing to uphold its responsibilities to all NHS patients? Health Econ. 2015;24:1-7.

26. Frederick S, Novemsky N, Wang J, Dhar R, Nowlis S. Opportunity Cost Neglect. J Consum Res. 2009;36:553-61.

27. Persson E, Tinghög G. Opportunity cost neglect in public policy. J Econ Behav Organ. 2020;170:301-12.

28. Brouwer W, van Baal P, van Exel J, Versteegh M. When is it too expensive? Cost-effectiveness thresholds and health care decision-making. Eur $J$ Health Econ. 2019;20:175-80.

29. Chen TC, Wanniarachige D, Murphy S, Lockhart K, O'Mahony J. Surveying the Cost-Effectiveness of the 20 Procedures with the Largest Public Health Services Waiting Lists in Ireland: Implications for Ireland's Cost-Effectiveness Threshold. Value Health. 2018;21:897-904. 
30. van Baal P, Perry-Duxbury $\mathbf{M}$, Bakx P, Versteegh M, van Doorslaer E, Brouwer W. A cost-effectiveness threshold based on the marginal returns of cardiovascular hospital spending. Health Econ. 2019;28:87-100.

31. Paulden M. Calculating and Interpreting ICERs and Net Benefit. Pharmacoeconomics. 2020;38:785-807. 